\title{
EFFECT OF LOW-TEMPERATURE TEMPERING ON THE PROPERTIES OF STRUCTURAL CARBIDE-FREE BAINITIC STEELS
}

\author{
A. Yu. Kaletin*, Yu. V. Kaletina \\ M.N. Miheev Institute of Metal Physics, Ural Branch of the Russian Academy of Sciences, \\ 18 S. Kovalevskoy St., Ekaterinburg, Russian Federation

\begin{abstract}
*Corresponding author. E-mail: akalet@imp.uran.ru; address for correspondence: 18, ul. S. Kovalevskoy, 620990, Ekaterinburg, Russian Federation. Tel.: +7 3433783818
\end{abstract}

Mechanical properties of chromium-nickel-molybdenum-silicon steels with carbon contents of $0.18 \%$ and $0.27 \%$ after slow continuous cooling with the cooling rate $V_{\text {cool }}=5{ }^{\circ} \mathrm{C} / \mathrm{min}$ in the bainitic temperature range are investigated. It is shown that, after this heat treatment, a carbide-free bainitic structure is formed in the investigated steels, which is a two-phase mixture of carbon-depleted bainitic ferrite and carbon-enriched retained austenite with different morphology. The retained austenite in the carbide-free bainite is substantially enriched with carbon and contains its considerable part from the total carbon content in the steel. It is demonstrated that tempering for $1 . . .2$ hours at a temperature of $300{ }^{\circ} \mathrm{C}$ raises the values of impact strength of the $18 \mathrm{Kh} 2 \mathrm{~N} 2 \mathrm{SM}$ and $27 \mathrm{Kh} 2 \mathrm{~N} 2 \mathrm{SM}$ steels after slow continuous cooling, which have a different proportion of lower lath and upper globular bainite, retained austenite and martensite in their structure.

It has been found that such tempering is accompanied by retained austenite stabilization due to a noticeable increase in carbon content in it.

Keywords: continuous cooling, carbide-free bainite, retained austenite, bainitic ferrite, carbon, cementite, mechanical properties, strength, impact strength.

DOI: $10.17804 / 2410-9908.2016 .6 .063-068$

\section{References}

1. Bojarski Z., Bold T. Structure and properties of carbide-free-bainite. Acta Metallurgica, 1974, vol. 22, iss. 10, pp. 1223-1234. DOI: 10.1016/0001-6160(74)90136-9.

2. Caballero F.G., Bhadeshia H.K.D.H. Very strong bainite. Current Opinion in Solid State and Materials Science, 2004, vol. 8, iss. 3, pp. 251-257. DOI:10.1016/j.cossms.2004.09.005.

3. García-Mateo C., Caballero F.G., Bhadeshia H.K.D.H. Mechanical Properties of LowTemperature Bainite. Materials Science Forum, 2005, vols. 500-501, pp. 495-502. DOI: 10.4028/www.scientific.net/MSF.500-501.495.

4. Bhadeshia H.K.D.H., Edmonds D.V. Bainite in silicon steels: new composition-property approach. Part I. Metal Science, 1983, vol. 17, iss. 9, pp. 411-419. DOI: $10.1179 / 030634583790420600$.

5. Khotinov V.A., Farber V.M., Morozova A.N. Evaluating the toughness of pipe steels by impact fracture curves. Diagnostics, Resource and Mechanics of materials and structures, 2015, iss. 2, pp. 57-66. DOI: 10.17804/2410-9908.2015.2.057-066. Available at: http://dreamjournal.org/DREAM_Issue_2_2015_Khotinov_V.A._et_al._57_66.pdf.

6. Georgiev M.N., Kaletin A.Yu., Simonov Yu.N., Schastlivtsev V.M. Effect of stability of retained austenite on the crack resistance of structural steel. Fiz. Met. Metalloved., 1990, iss. 1, pp. 113-121. (In Russian).

7. Kaletin A.Yu., Ryzhkov A.G., KaletinaYu.V. Enhancement of impact toughness of structural steels upon formation of carbide-free bainite. The Physics of Metals and Metallography, 2015, vol. 116, no. 1, pp. 114-120. (In Russian). 
ittn.//[ream-journal.0i"l]

8. Caballero F.G., Garcia-Mateo C., Santofimia M.J., Miller M.K., Garcia de Andres C. New experimental evidence on the incomplete transformation phenomenon in steel. Acta Materialia, 2009, vol. 57, iss. 1, pp. 8-17. DOI: 10.1016/j.actamat.2008.08.041.

9. Caballero F.G., Miller M.K., Babu S.S., Garcia-Mateo C. Atomic scale observations of bainite transformation in a high carbon high silicon steel. Acta Materialia, 2007, vol. 55, iss. 1, pp. 381-390. DOI: 10.1016/j.actamat.2006.08.033.

10. Shchastlivtsev V.M., Kaletina Yu.V., Smirnov M.A., Kaletin A.Yu. The structure and properties of structural steels after thermomechanical treatment in the bainitic temperature range. Deformatsiya i razrushenie materialov, 2011, no. 4. pp. 1-9 (In Russian).

Kaletin A.Yu. et al. / Effect of low-temperature tempering on the properties of structural carbide-free bainitic steels 
Подана в журнал: 09.11.2016

УДК 669.14.018.29:539.4.015

DOI: $10.17804 / 2410-9908.2016 .6 .063-068$

\title{
ВЛИЯНИЕ НИЗКОГО ОТПУСКА НА СВОЙСТВА КОНСТРУКЦИОННЫХ СТАЛЕЙ С БЕСКАРБИДНЫМ БЕЙНИТОМ
}

\author{
А. Ю. Калетин*, Ю. В. Калетина \\ Федеральное государственное бюджетное учреждение науки Институт физики металлов \\ имени М.Н. Михеева Уральского отделения Российской академии наук, \\ ул. С. Ковалевской, 18, Екатеринбург, Российская Федерация \\ *Ответственный автор. Электронная почта: akalet@imp.uran.ru; адрес для переписки: ул. С. Ковалевской, 18, \\ 620990, Екатеринбург, Российская Федерация. Телефон: +7 (343) 378-38-18
}

Исследованы механические свойства хромоникельмолибденовых кремнистых сталей с содержанием углерода 0,18 и 0,27 \% после медленного непрерывного охлаждения в бейнитной области со скоростью $V_{\text {охл }}=5{ }^{\circ} \mathrm{C} /$ мин. Показано, что после такого режима термической обработки в исследованных сталях образуется структура бескарбидного бейнита, представляющая собой двухфазную смесь обедненного по углероду бейнитного феррита и пересыщенного углеродом остаточного аустенита различной морфологии. Остаточный аустенит в бескарбидном бейните существенно обогащен по углероду и содержит значительную часть от общего содержания углерода в стали. Показано, что отпуск при температуре $300{ }^{\circ} \mathrm{C}$ в течение $1 . . .2$ ч повышает значения ударной вязкости сталей $18 \mathrm{X} 2 \mathrm{H} 2 \mathrm{CM}$ и $27 \mathrm{X} 2 \mathrm{H} 2 \mathrm{CM}$ после медленного непрерывного охлаждения, имеющих в структуре различное соотношение как нижнего реечного, так и верхнего глобулярного бейнита, остаточного аустенита и мартенсита. Установлено, что при таком отпуске происходит стабилизация остаточного аустенита за счет заметного повышения в нем содержания углерода.

Ключевые слова: непрерывное охлаждение, бескарбидный бейнит, остаточный аустенит, бейнитный феррит, углерод, механические свойства, прочность, ударная вязкость.

\section{1. Введение}

В настоящее время использование сталей бейнитного класса для производства ответственных деталей и конструкций вызывает повышенный интерес. Такие стали обладают повышенным комплексом механических и эксплуатационных свойств, достаточно технологичны и при экономном легировании характеризуются пониженной стоимостью. Интерес к переходу на стали бейнитного класса проявляют производители железнодорожных рельсов, поскольку возможности дальнейшего улучшения эксплуатационных характеристик рельсов из перлитной стали оказались исчерпаны. Практика использования трубных сталей также показывает, что при формировании в них феррито-перлитной структуры невозможно получить требуемые функциональные характеристики. Высокие прочностные свойства этих сталей обеспечивают режимы термообработки, при которых формируются феррито-бейнитная, чисто бейнитная или бейнитно-мартенситная структуры.

Бейнитная структура имеет сложную природу и может существенно изменять свою морфологию в зависимости от содержания в стали углерода, легирующих элементов и условий охлаждения. В настоящее время о промежуточном превращении переохлажденного аустенита [1-2] и свойствах бейнита конструкционных сталей [2-10] накоплен большой материал. Проявлением многообразия бейнитной структуры в зависимости от легирования и особенностей термической обработки стали является возникновение структуры так называемого «бескарбидного бейнита», представляющего собой сочетание малоуглеродистого бейKaletin A.Yu. et al. / Effect of low-temperature tempering on the properties of structural

carbide-free bainitic steels 
нитного феррита и высокоуглеродистого остаточного аустенита. Бескарбидный бейнит может быть верхним и нижним, но в любом случае в нем отсутствуют выделения карбидов. На протяжении последних десятилетий исследованием структуры бескарбидного бейнита занимаются многие ученые в различных странах мира [6-10]. Такой значительный интерес к данной проблеме объясняется тем, что стали с подобной структурой обладают сочетанием высокой прочности и ударной вязкости.

Несмотря на большое количество данных, относительно особенностей структуры бескарбидного бейнита, существует ряд нерешенных вопросов, касающихся влияния отпуска на механические свойства среднелегированных конструкционных сталей со структурой бескарбидного бейнита.

В связи с этим цель настоящей работы - исследование влияния отпуска при различных температурах на поведение остаточного аустенита и механические свойства сталей с бескарбидным бейнитом, полученным при непрерывном медленном охлаждении в бейнитном интервале температур.

\section{2. Материал и методика исследования}

Исследовали структуру и свойства легированных сталей, химический состав которых приведен в табл. 1.

Таблица 1 - Химический состав исследованных сталей, мас. \%

\begin{tabular}{|l|c|c|c|c|c|c|c|c|}
\hline Сталь & $\mathrm{C}$ & $\mathrm{Cr}$ & $\mathrm{Ni}$ & $\mathrm{Mn}$ & $\mathrm{Si}$ & $\mathrm{Mo}$ & $\mathrm{S}$ & $\mathrm{P}$ \\
\hline $27 \mathrm{X} 2 \mathrm{H} 2 \mathrm{CM}$ & 0,27 & 1,75 & 1,96 & 0,36 & 0,93 & 0,40 & 0,015 & 0,010 \\
\hline 18 Х2H2CM & 0,18 & 1,78 & 2,10 & 0,34 & 0,98 & 0,43 & 0,013 & 0,010 \\
\hline
\end{tabular}

Заготовки исследуемых сталей $18 \mathrm{X} 2 \mathrm{H} 2 \mathrm{CM}$ и $27 \mathrm{X} 2 \mathrm{H} 2 \mathrm{CM}$ нагревали на $870{ }^{\circ} \mathrm{C}$, выдерживали 30 мин, после чего охлаждали с печью с постоянной скоростью $V_{\text {охл }}=5^{\circ} \mathrm{C} /$ мин. В результате такой обработки получали бейнитную структуру. Микроструктуру сталей изучали электронно-микроскопическим методом на микроскопе JEM-200 CX на фольгах, вырезанных из соответствующих образцов, приготовленных по стандартной методике. Количество остаточного аустенита измеряли магнитометрическим методом. Механические свойства определяли при комнатной температуре. Ударную вязкость определяли на образцах типа I по ГОСТ 9454-78. Для определения параметра решетки остаточного аустенита на аппарате ДРОН-3,0 в $\mathrm{K}_{\alpha}$-излучении железа снимали линию (311) $\gamma$. Содержание углерода в остаточном аустените определяли по параметру кристаллической решетки.

\section{3. Результаты и обсуждение}

В отличие от изотермической закалки, когда бейнитную структуру получают преднамеренно, образование бейнита при закалке в центральных участках массивных изделий является нежелательным, но довольно частым явлением. При этом образование бейнитной структуры протекает во всем температурном интервале превращения. При непрерывном охлаждении исследованных сталей 18Х2Н2СМ и 27Х2Н2СМ формируется структура, состоящая из кристаллов бейнитного феррита реечной и глобулярной формы, остаточного аустенита с различным содержанием углерода, при распаде которого дополнительно может образовываться мартенсит. Электронно-микроскопические исследования показали, что отличительной особенностью структуры бейнита исследованных хромоникельмолибденовых сталей является полное отсутствие карбидов. Естественно, что сталь с такой структурой необходимо отпускать. Как видно из табл. 3, ударная вяз-

Kaletin A.Yu. et al. / Effect of low-temperature tempering on the properties of structural carbide-free bainitic steels 
кость сталей $18 \mathrm{X} 2 \mathrm{H} 2 \mathrm{CM}$ и 27Х2Н2СМ после такого отпуска несколько повышается при сохранении твердости на уровне неотпущенных образцов.

Таблица 2 - Влияние режимов термообработки на механические свойства, количество остаточного аустенита (О.А.) и содержание в нем углерода в стали $18 \mathrm{X} 2 \mathrm{H} 2 \mathrm{CM}$ и 27X2H2CM с исходной бейнитной структурой

\begin{tabular}{|c|c|c|c|c|c|c|}
\hline $\begin{array}{l}\text { Марка } \\
\text { стали }\end{array}$ & $\begin{array}{c}\text { Режим } \\
\text { отпуска }\end{array}$ & $\begin{array}{c}\text { Твер- } \\
\text { дость, } \\
\text { НВ }\end{array}$ & 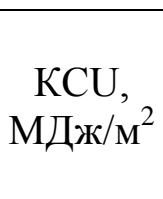 & $\begin{array}{l}\text { Кол-во } \\
\text { О.А., \% }\end{array}$ & $\begin{array}{c}\text { Содержа- } \\
\text { ние C } \\
\text { в О.А., \% }\end{array}$ & $\begin{array}{c}\text { Обогаще- } \\
\text { ние ОА } \\
\text { углеродом, } \\
\%\end{array}$ \\
\hline \multirow[t]{2}{*}{ 18X2H2CM } & $\begin{array}{c}\text { Без } \\
\text { отпуска }\end{array}$ & 352 & 0,9 & 16 & 1,0 & $+0,82$ \\
\hline & $\begin{array}{l}\text { Отпуск } \\
300{ }^{\circ} \mathrm{C}\end{array}$ & 352 & 1,0 & 14 & 1,13 & $+0,95$ \\
\hline \multirow[t]{2}{*}{ 27X2H2CM } & $\begin{array}{c}\text { Без } \\
\text { отпуска }\end{array}$ & 352 & 0,85 & 22 & 1,08 & $+0,8$ \\
\hline & $\begin{array}{l}\text { Отпуск } \\
300^{\circ} \mathrm{C}\end{array}$ & 363 & 0,90 & 19 & 1,26 & $+1,0$ \\
\hline
\end{tabular}

Результаты рентгеноструктуроного анализа исследуемых сталей с бейнитной структурой, образовавшейся при непрерывном охлаждении с печью, до и после отпуска на $300{ }^{\circ} \mathrm{C}$ приведены в табл. 2. Видно, что низкотемпературный отпуск приводит к некоторому уменьшению количества остаточного аустенита в структуре сталей $18 \mathrm{X} 2 \mathrm{H} 2 \mathrm{CM}$ и $27 \mathrm{X} 2 \mathrm{H} 2 \mathrm{CM}$ соответственно на $2 \%$ и 3 \% при этом происходит увеличение параметра решетки $\gamma$-фазы. Согласно расчетам, проведенным по методике [1], содержание углерода в остаточном аустените в случае 300-градусного отпуска повышается на 0,13...0,18 \%. По-видимому, это связано с распадом остаточного аустенита во время отпуска по бейнитному механизму, при этом некоторая его часть превращается в низкоуглеродистый бейнитный феррит без выделения карбидов, и происходит дальнейшее обогащение непревращенного остаточного аустенита углеродом.

Проведенное электронно-микроскопическое исследование сталей $18 \mathrm{X} 2 \mathrm{H} 2 \mathrm{CM}$ и $27 \mathrm{X} 2 \mathrm{H} 2 \mathrm{CM}$ с бейнитной структурой после отпуска на $300{ }^{\circ} \mathrm{C}$ не выявило существенных изменений. В структуре обеих сталей наблюдаются глобулярные и реечные кристаллы бейнитного феррита с участками остаточного аустенита. Выделений карбидов ни в бейнитном феррите, ни в остаточном аустените обнаружено не было.

Можно заключить, что низкотемпературный отпуск сталей со структурой бескарбидного бейнита, не вызывающий выделение карбидов, приводит к обогащению остаточного аустенита углеродом, т.е. к его стабилизации, и, как следствие, к повышению сопротивления стали ударному разрушению. Наблюдается также некоторое повышение ударной вязкости при испытаниях в области отрицательных температур: при температуре $-60{ }^{\circ} \mathrm{C}$ ударная вязкость стали 27Х2Н2СМ с бейнитной структурой составляет 0,50 МДж/ ${ }^{2}$, а после 300 -градусного отпуска - 0,55 МДж/м². Это решает проблему широкого использования низкоуглеродистых хромоникельмолибденовых сталей, рекомендуемых для массивных деталей. Как уже указывалось в работе [7], при непрерывном охлаждении от температуры аустонизации в различных участках по сечению образцов из сталей 10Х2Н3ГМ, 14Х2Н2ГМФ, I8X2H2CM, 27X2H2CM образуется бескарбидный глобулярный и реечный бейнит, сохраняется остаточный аустенит и не исключается вероятность образования мартенсита в участках, прилегающих к поверхности. Как показывают результаты настоящего исследования, низкотемпературный отпуск сталей с такой сложной структурой оказывается полезным.

Kaletin A.Yu. et al. / Effect of low-temperature tempering on the properties of structural carbide-free bainitic steels 


\section{4. Заключение}

Показано, что остаточный аустенит в бескарбидном бейните кремнистых сталей после непрерывного охлаждения существенно обогащен по углероду и содержит значительную часть от общего содержания углерода в стали. Установлено, что отпуск при температуре $300{ }^{\circ} \mathrm{C}$ в течение $1 \ldots 2$ ч повышает значения ударной вязкости сталей $18 \mathrm{X} 2 \mathrm{H} 2 \mathrm{CM}$ и 27Х2Н2СМ после медленного непрерывного охлаждения, имеющих в структуре различное соотношение как реечного - нижнего, так и глобулярного - верхнего бейнита, остаточного аустенита. Установлено, что при таком отпуске происходит стабилизация остаточного аустенита за счет заметного повышения в нем содержания углерода.

\section{Благодарность}

Работа выполнена в рамках государственного задания ФАНО России (тема «Кристалл», № 01201463333) при частичной поддержке проекта УрО РАН № 15-17-2-11. Электронно-микроскопическое исследование выполнено в ЦКП «Испытательный центр нанотехнологий и перспективных материалов» ИФМ УрО РАН.

\section{Литература}

1. Bojarski Z., Bold T. Structure and properties of carbide-free-bainite // Acta Metallurgica. 1974. - Vol. 22, iss. 10. - P. 1223-1234. - DOI: 10.1016/0001-6160(74)90136-9.

2. Caballero F. G., Bhadeshia H. K. D. H. Very strong bainite // Current Opinion in Solid State and Materials Science. - 2004. - Vol. 8, iss. 3. - P. 251-257. DOI: 10.1016/j.cossms.2004.09.005.

3. García-Mateo C., Caballero F. G., Bhadeshia H. K. D. H. Mechanical Properties of Low-Temperature Bainite // Materials Science Forum. - 2005. - Vols. 500-501. - P. 495-502. DOI: 10.4028/www.scientific.net/MSF.500-501.495.

4. Bhadeshia H. K. D. H., Edmonds D. V. Bainite in silicon steels: new composition-property approach. Part I // Metal Science. - 1983. - Vol. 17, iss. 9. - P. 411-419. DOI: $10.1179 / 030634583790420600$.

5. Khotinov V. A., Farber V. M., Morozova A. N. Evaluating the toughness of pipe steels by impact fracture curves // Diagnostics, Resource and Mechanics of materials and structures. - 2015. Iss. 2. - P. 57-66. - DOI: 10.17804/2410-9908.2015.2.057-066. - URL: http://dreamjournal.org/DREAM_Issue_2_2015_Khotinov_V.A._et_al._57_66.pdf.

6. Effect of stability of retained austenite on the crack resistance of structural steel / M. N. Georgiev, A. Yu. Kaletin, Yu. N. Simonov, V. M. Schastlivtsev // Fiz. Met. Metalloved. 1990. - Iss. 1. - P. 113-121. (In Russian).

7. Kaletin A. Yu., Ryzhkov A. G., Kaletina Yu. V. Enhancement of impact toughness of structural steels upon formation of carbide-free bainite // The Physics of Metals and Metallography. 2015. - Vol. 116, no. 1. - P. 114-120. (In Russian).

8. New experimental evidence on the incomplete transformation phenomenon in steel / F. G. Caballero, C. Garcia-Mateo, M. J. Santofimia, M. K. Miller, C. Garcia de Andres // Acta Materialia. - 2009. - Vol. 57, iss. 1. - P. 8-17. - DOI: 10.1016/j.actamat.2008.08.041.

9. Atomic scale observations of bainite transformation in a high carbon high silicon steel / F. G. Caballero, M. K. Miller, S. S. Babu, C. Garcia-Mateo // Acta Materialia. - 2007. - Vol. 55, iss. 1. - P. 381-390. - DOI: 10.1016/j.actamat.2006.08.033.

10. Структура и свойства конструкционных сталей после термомеханической обработки в бейнитной области температур / В. М. Счастливцев, Ю. В. Калетина, М. А. Смирнов, А. Ю. Калетин // Деформация и разрушение материалов. - 2011. - № 4. C. $1-9$.

Kaletin A.Yu. et al. / Effect of low-temperature tempering on the properties of structural carbide-free bainitic steels 